\title{
The Evaluation and Analysis of Urbanization Efficiency in West China
}

\author{
Qiaohong Guo
}

School of Finance, Guizhou University of Finance and Economics, Guiyang Guizhou 550025, China

\begin{abstract}
In the rapid development of urbanization, it is very important to improve the efficiency of urbanization. Based on the data of input and output in the western provinces from 2013 to 2015, this paper chooses five input indicators from the three perspectives (land, capital and labor force), and four output indicators from the perspective of urbanization. This paper uses the input-oriented BCC model to evaluate the urbanization efficiency of the western provinces in 2015 . The Malmquist-DEA model was used to analyze the urbanization efficiency of the western provinces in 2013-2015. The results show that in 2015, Tibet, Qinghai, and Ningxia achieved the effective of DEA, the remaining seven provinces failed to achieve the effective of DEA; 2013 to 2015, the urbanization production efficiency of the western region displayed a downward trend. Generally, the development trend of urbanization efficiency in the western region was declining.
\end{abstract}

\section{Keywords}

Urbanization efficiency; western region; DEA - BCC model; Malmquist index

\section{西部地区城镇化效率评价分析}

\author{
郭乔虹 \\ 贵州财经大学金融学院, 贵阳 550025, 中国
}

摘要: 在加快城镇化发展过程中, 提高城镇化效率尤为重要。本文基于 2013-2015 年西部地 区各省份的数据建立投入产出指标体系，从土地、资本和劳动力三个角度选取 5 个投入指 标, 从城镇化角度选取 4 个产出指标, 并利用投入导向型的 BCC 模型对 2015 年西部地区各 省份城镇化效率进行静态测评, 运用 Malmquist DEA 模型对 2013-2015 年西部地区各省份的 城镇化效率进行动态分析。结果显示 2015 年, 西部地区西藏、青海、宁夏实现 DEA 有效, 其余七个省份未能实现 DEA 有效; 2013 年到 2015 年, 西部各省的城镇化生产效率在 3 年 内也均呈现出下降的趋势。整体来说, 西部地区城镇化效率发展趋势减缓。

关键词：城镇化效率; 西部地区; DEA-BCC 模型; Malmquist 指数

1. 前言

This is an open access article under the CC BY-NC license (http://creativecommons.org/licenses/by-nc/4.0/). 
面, 是农村人口转变为城镇人口的过 程, 是二、三产业比重逐渐加强的产 业结构转变的过程, 也是扩大城镇规 模, 加强基础设施建设, 实现城乡一 体化发展的过程。其实质是经济结 构、社会结构和空间结构的变迁 ${ }^{[1]}$ 。 改革开放以来, 我国的城镇化逐步推 进, 2013 年, 在供给侧改革的背景 下, 我国进入新型城镇化发展的阶 段。新型城镇化要求在积极推进城镇 化进程中, 提高城镇化发展质量, 引 导城镇化积极健康发展。因此, 对城 镇化效率问题的研究显得尤为重要。

中国的城镇化进程不断推进, 但 地区发展不平衡, 西部地区较东部地 区整体发展比较缓慢, 且西部地区内 部各省市城镇化发展存在一定的差 距。因此本文以西部地区作为研究对 象, 选取了重庆、四川、贵州、云 南、西藏、陕西、甘肃、青海、宁 夏、新疆等 10 个省、自治区以及直辖 市作为样本地区, 对其城镇化效率进 行研究。

\section{2. 研究方法与数据}

\section{1. 模型与方法}

(1) DEA 模型。数据包络分析 (DEA) 最先由美国著名运筹学家 Charnes ${ }^{[2]}$ 等 (1978) 提出, 其借助数 学规划, 对多个输出与输入的决策单 元进行相对效率的评价, 根据研究角 度的不同，分为投入导向型和产出导 向型。目前, 应用最广泛的有 CCR (规模报酬不变) 和 $\mathrm{BCC}^{[3]}$ （规模报 酬可变) 两种模型。

(2) Malmquist DEA 模型。对于 面板数据, 运用 Malmquist DEA 模型 能够实现对效率动态变化的描述。指 数大于 1 时, 效率提高; 指数等于 1 时, 效率不变; 指数小于 1 时, 效率 降低。
本文以 2013-2015 年我国西部十个 省份为研究对象, 利用产出导向型的 BCC 模型对 2015 年西部十个省份城镇 化效率进行静态测评, 运用 Malmquist DEA 模型对 2013-2015 年西部十个省 份的城镇化效率进行动态测评。

\section{2. 指标的选取}

国内关于城镇化效率的研究成果 较为丰富, 在测度城镇化效率指标的 选取上, 大部分学者将土地、劳动力 和资本作为投入指标 ${ }^{[4-8]}$, 将城镇人口 数或人口城镇化率作为产出指标 ${ }^{[4,5,7}$ 9], 为健全指标体系, 一些学者将一些 经济指标（如 GDP、居民消费水平 等) 和社会指标加入产出指标体系 ${ }^{[4}$, $6,7,9]$, 张明斗 ${ }^{\left[6^{]}\right]}$将人均拥有道路面积 及人均拥有绿地面积指标纳入产出指 标体系。魏后凯等 ${ }^{[9]}$ 基于资源环境效 率的视角从能源、水资源和土地资源 等方面选取投入指标。

本文综合前人的研究基础, 并考 虑指标选取的可得性与合理性的原 则, 将投入指标设置为三个方面, 土 地的投入、资本的投入和劳动力的投 入。其中土地指标设置为城市建设用 地面积，资本的投入包括固定资产投 资、财政支出与外商投资，劳动力的 投入用城镇就业人口指标表示。由 于, 新型城镇化建设强调城乡一体化 发展, 因此将城乡一体化发展作为一 项产出指标。产出指标包括人口的城 镇化、经济的城镇化、社会的城镇化 和城乡一体化四个方面。具体指标体 系如表 1 所示。 
表 1 城镇化效率评价指标体系

\begin{tabular}{|c|c|c|}
\hline 指标类别 & 指标体系 & \\
\hline \multirow{4}{*}{ 投入指标 } & 土地 & 城市建设用地面积 \\
\hline & \multirow{3}{*}{ 资本 } & 城镇固定资产投资总额 \\
\hline & & 财政支出 ～～～～～ \\
\hline & & $\begin{array}{l}\text { 外商投资企业投资总额 } \\
\text { (百万美元) }\end{array}$ \\
\hline & 劳动力 & 城镇就业人口数 \\
\hline \multirow{4}{*}{ 产出指标 } & $\begin{array}{l}\text { 人口城镇 } \\
\text { 化 }\end{array}$ & 城镇人口/总人口 \\
\hline & $\begin{array}{l}\text { 经济城镇 } \\
\text { 化 }\end{array}$ & 二三产业产值/GDP \\
\hline & $\begin{array}{l}\text { 社会城镇 } \\
\text { 化 }\end{array}$ & 居民消费水平 \\
\hline & 城乡一体 & $\begin{array}{l}\text { 农村居民人均可支配收入/ } \\
\text { 城镇居民人均可支配收入 }\end{array}$ \\
\hline
\end{tabular}

\section{3. 数据说明}

本文采用 2013-2015 年西部十个省 份的投入产出数据, 且指标数据资料 均取自《中国统计年鉴》及国民经济 和社会发展统计公报及其计算所得。

\section{3. 西部地区城镇化效率实证分析}

\subsection{5 年城镇化效率测评}

（1）效率评价。如表 2 所示。从 综合效率角度来看 (综合效率为纯技 术效率与规模效率的乘积），2015 年, 只有西藏、青海、宁夏三个省份 综合效率为 1 , 能够实现 DEA 有效, 重庆、四川、贵州、云南、陕西、甘 肃、新疆共七个省份均为实现 DEA 有 效, 且综合效率较低。从纯技术效率 角度来看, 2015 年, 贵州、云南、陕 西、甘肃、新疆五个省份的纯技术效 率不为 1 , 重庆、四川、西藏、青海、 宁夏等地的纯技术为 1 , 说明贵州、云 南、陕西、甘肃、新疆五个省份技术 水平和管理水平相对较弱。从规模效 率和规模报酬角度来看，只有西藏、 青海、宁夏三个省份的效率为 1 且均 为规模报酬不变，而重庆、四川、贵 州、云南、陕西、甘肃、新疆等七个
省份规模效率均低于 0.5 , 且均表现为 规模报酬递减。

综合来说, 西部地区平均综合效 率值 0.511 , 表明西部地区的城镇化效 率在现有资源的投入水平下，总体未 能实现产出的有效性。大部分省份综 合效率较低的原因主要是规模效率的 水平较低, 且重庆、四川、贵州、云 南、陕西、甘肃、新疆等七个省份规 模效率均低于平均水平, 说明这些省 份应该合理配置资源, 提高生产的规 模效率。

表 2 西部各省份 2015 年城镇化效率评价结果

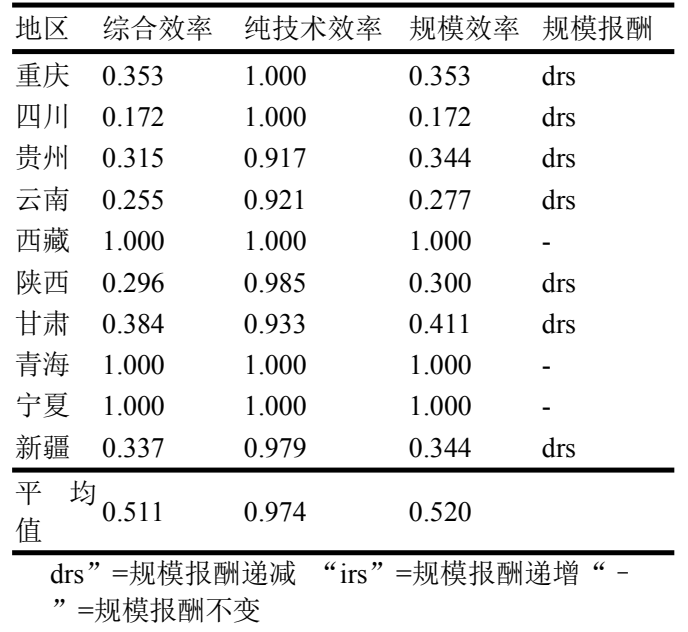

(2) 投入圥余与产出不足评价。 2015 年, 贵州、云南、陕西、甘肃和 新疆等五个地区出现投入圥余与产出 不足的情况。以贵州为例进行具体分 析（见表 3），贵州在现有投入的水平 下，人口城镇化率、经济城镇化率、 居民消费水平、城乡一体化应分别增 加到 $56.624 \%$ 、 $92.037 \%$ 、 17611.966 元和 $36.785 \%$, 或要维持现有的产出水 平，城市建设用地面积、城镇固定资 产投资总额、财政支出、城镇就业人 口数等投入分别减少 139.673 平方公 里、4623.68 亿元、2154.573 亿元、 95.925 万人，外商投资企业投资总额 未出现投入穴余的情况。 
表 32015 年贵州省出现投入咒余与产出不足情 况汇总表

\begin{tabular}{|c|c|c|c|c|}
\hline 指标 & 原始值 & $\begin{array}{l}\text { 投入咒 } \\
\text { 余值 }\end{array}$ & $\begin{array}{l}\text { 产出不 } \\
\text { 足值 }\end{array}$ & $\begin{array}{l}\text { DEA 有 效 } \\
\text { 的目标值 }\end{array}$ \\
\hline 人口城镇化率 & 42.010 & 3.812 & 10.802 & 56.624 \\
\hline 经济城镇化率 & 84.380 & 7.657 & 0.000 & 92.037 \\
\hline 居民消费水平 & $\begin{array}{l}12876.0 \\
00\end{array}$ & $\begin{array}{l}1168.43 \\
4\end{array}$ & $\begin{array}{l}3567.5 \\
32\end{array}$ & 17611.966 \\
\hline 城乡一体化 & 30.050 & 2.727 & 4.008 & 36.785 \\
\hline $\begin{array}{l}\text { 城市建设用地面 } \\
\text { 积 }\end{array}$ & 702.000 & 0.000 & $\begin{array}{l}- \\
139.67 \\
3\end{array}$ & 562.327 \\
\hline $\begin{array}{l}\text { 城镇固定资产投 } \\
\text { 资总额 }\end{array}$ & $\begin{array}{l}10676.7 \\
00\end{array}$ & 0.000 & $\begin{array}{l}- \\
4623.6 \\
80\end{array}$ & 6053.020 \\
\hline 财政支出 & $\begin{array}{l}3939.50 \\
0\end{array}$ & 0.000 & $\begin{array}{l}- \\
2154.5 \\
73\end{array}$ & 1784.927 \\
\hline $\begin{array}{l}\text { 外商投资企业投 } \\
\text { 资总额 }\end{array}$ & $\begin{array}{l}1662.00 \\
0\end{array}$ & 0.000 & 0.000 & 1662.000 \\
\hline 城镇就业人口数 & 500.140 & 0.000 & -95.925 & 404.215 \\
\hline
\end{tabular}

\subsection{3-2015 年城镇化效率测评}

表 4 是西部地区各省份 2013 年到 2015 年各年基于规模报酬不变得出的 综合效率, 若其值为 1 , 则对应的决策 单元的城镇化效率相对有效; 若小于 1 , 则城镇化效率相对无效。如表 4 所 示, 2013 年, 贵州、云南、陕西和甘 肃四个地区城镇化效率相对无效, 重 庆、四川、西藏、青海、宁夏、新疆 等六个地区均实现 DEA 有效; 2014 年, 贵州、云南、陕西和甘肃四个地 区仍表现为 DEA 无效; 2015 年，贵 州、云南、陕西、甘肃、新疆五个地 区城镇化效率相对无效, 重庆、四 川、西藏、青海、宁夏五个省份均实 现 DEA 相对有效。

综合来看，在规模报酬不变的情 况下, 西部地区各省份 2013 年到 2015 年之间的综合技术效率均大于 0.9 , 且 整个西部地区连续三年综合技术效率 平均值均大于 0.97 , 说明西部地区城 镇化效率基本能够实现高效率的投入 产出, 而贵州、云南、陕西和甘肃四 个地区的综合技术效率连续三年均未
实现 DEA 有效, 但是其差距较小, 需 要提高技术方面的能力和管理水平。

表 4 西部各省 2013-2015 年综合技术效率

\begin{tabular}{llll}
\hline 年份/地区 & 2013 & 2014 & 2015 \\
\hline 重庆 & 1.000 & 1.000 & 1.000 \\
四川 & 1.000 & 1.000 & 1.000 \\
贵州 & 0.954 & 0.935 & 0.917 \\
云南 & 0.915 & 0.914 & 0.921 \\
西藏 & 1.000 & 1.000 & 1.000 \\
陕西 & 0.988 & 0.986 & 0.985 \\
甘肃 & 0.943 & 0.941 & 0.933 \\
青海 & 1.000 & 1.000 & 1.000 \\
宁夏 & 1.000 & 1.000 & 1.000 \\
新疆 & 1.000 & 1.000 & 0.979 \\
\hline 平均值 & 0.980 & 0.977 & 0.974 \\
\hline
\end{tabular}

Malmquist 指数能够综合反映城镇 化效率, 并将其变动分为技术效率变 动和技术进步且全要素生产率变动为 两者的乘积, 技术效率又可分为规模 效率变动与纯技术效率变动引起的技 术效率变动且技术效率变动为规模效 率变动与纯技术效率变动的乘积。如 表 5 所示, 综合西部地区的平均 Malmquist 指数及其分解来看，2013 年 到 2014 年间，技术效率变动、技术变 动、纯技术效率变动、规模效率变动 均小于 1 , 使得全要素生产率变动小于 1, 即 Malmquist 指数小于 1, 说明西 部地区城镇化生产效率在 2013-2014 年 间有所下降； 2014 年到 2015 年间，技 术效率变动、技术变动、纯技术效率 变动、规模效率变动均小于 1 , 使得全 要素生产率变动小于 1 , 说明西部地区 城镇化生产效率在 2013-2014 年间仍然 有所下降。

综合西部地区平均城镇化效率的 Malmquist 指数来看, 三年间西部地区 平均全要素生产率均表现为下降的趋 势, 说明西部地区城镇化整体发展逐 渐减缓。 
表 5 2013-2015 年西部地区平均城镇化效率 Malmquist 指数及分解

\begin{tabular}{llllll}
\hline \multirow{2}{*}{ 年份 } & \multicolumn{6}{c}{$\begin{array}{l}\text { 技术效技 术纯技术效规模效全要素生 } \\
\text { 率变动 进步 }\end{array}$} & 率变动 & 率变动 & 产率变动 \\
\hline 2014 & 0.996 & 0.959 & 0.997 & 0.998 & 0.955 \\
2015 & 0.994 & 0.945 & 0.996 & 0.998 & 0.94 \\
\hline $\begin{array}{l}\text { 平 均 } \\
\text { 值 }\end{array}$ & 0.995 & 0.952 & 0.997 & 0.998 & 0.947 \\
\hline
\end{tabular}

西部地区各省的 Malmquist 指数及 分解如表 6 所示, 十个省份的全要素 生产率均小于 1 , 均为负向增长。其 中, 甘肃省的全要素生产率下降达到 $10.6 \%$, 青海省的全要素生产率下降最 小，为 $0.7 \%$, 重庆、陕西、西藏、宁 夏、云南、四川、新疆、贵州等地的 全要素生产率分别下降 3.30\%、 $3.50 \% 、 3.70 \% 、 4.20 \% 、 4.50 \%$ 、 $5.60 \% 、 7.00 \% 、 9.20 \%$ 。十个省份中， 仅有重庆市的技术变动大于 1 , 说明西 部地区整体来说技术方面表现为退 步, 但重庆市的规模效率变动小于 1 , 使得技术效率变动小于 1 , 说明其应合 理配置投入资源，提高其规模效率。 四川、云南、西藏、青海和宁夏五个 地区因技术效率变动大于等于 1 , 使得 全要素生产效率小于 1 , 说明五个地区 应该在技术进步方面加大投入。贵州 和新疆技术变动和纯技术效率变动均 小于 1 , 说明两个省份在加强技术进步 的基础上应该提高技术使用效率和管 理水平。陕西和甘肃两个地区的技术 效率变动、技术变动、纯技术效率变 动、规模效率变动均小于 1 , 说明两个 地区应提高技术水平，合理配置资 源, 促进城镇化的平衡发展。
表 6 2013-2015 年西部各省城镇化效率 Malmquist 指数及分解

\begin{tabular}{|c|c|c|c|c|c|}
\hline 地区 & $\begin{array}{l}\text { 技术交 } \\
\text { 率变动 }\end{array}$ & 进步 & 率变动 & $\begin{array}{l}\text { 规椇父 } \\
\text { 率变动 }\end{array}$ & 产率变动 \\
\hline 重庆 & 0.958 & $\begin{array}{l}1.01 \\
0\end{array}$ & 1.000 & 0.958 & 0.967 \\
\hline 四川 & 1.021 & $\begin{array}{l}0.92 \\
5\end{array}$ & 1.000 & 1.021 & 0.944 \\
\hline 贵州 & 0.984 & $\begin{array}{l}0.92 \\
3\end{array}$ & 0.980 & 1.004 & 0.908 \\
\hline 云南 & 1.007 & $\begin{array}{l}0.94 \\
8\end{array}$ & 1.003 & 1.004 & 0.955 \\
\hline 西藏 & 1.000 & $\begin{array}{l}0.96 \\
3\end{array}$ & 1.000 & 1.000 & 0.963 \\
\hline 陕西 & 0.993 & $\begin{array}{l}0.97 \\
2\end{array}$ & 0.999 & 0.994 & 0.965 \\
\hline 甘肃 & 0.988 & $\begin{array}{l}0.90 \\
4\end{array}$ & 0.995 & 0.993 & 0.894 \\
\hline 青海 & 1.000 & $\begin{array}{l}0.99 \\
3\end{array}$ & 1.000 & 1.000 & 0.993 \\
\hline 宁夏 & 1.000 & $\begin{array}{l}0.95 \\
8\end{array}$ & 1.000 & 1.000 & 0.958 \\
\hline 新疆 & 1.000 & $\begin{array}{l}0.93 \\
0 \\
\end{array}$ & 0.989 & 1.011 & 0.930 \\
\hline $\begin{array}{l}\text { 平 均 } \\
\text { 值 }\end{array}$ & 0.995 & $\begin{array}{l}0.95 \\
2\end{array}$ & 0.997 & 0.998 & 0.947 \\
\hline
\end{tabular}

\section{4. 结论与建议}

本文基于 2013-2015 年西部地区各 省份的数据建立投入产出指标体系, 对 2013-2015 年西部地区各省份的城镇 化效率进行静态和动态分析。得出以 下结论：（1）通过对 2015 年西部地 区各省份的城镇化效率测评分析得 出, 2015 年, 西部地区西藏、青海、 宁夏三个省份综合效率为 1 , 能够实现 DEA 有效, 重庆、四川、贵州、云 南、陕西、甘肃、新疆七个省份均未 实现 DEA 有效。西部地区整体未能实 现城镇化效率的 DEA 有效。其中, 贵 州、云南、陕西、甘肃和新疆等五个 地区出现投入攵余与产出不足的情 况。（2）通过对 2013-2015 年西部地 区各省份城镇化效率综合技术效率测 评分析得出, 2013 年到 2015 年, 西部 地区的平均城镇化效率逐年下降，而 
各省份的城镇化效率在 3 年内也均呈 现出下降的趋势。

针对西部地区城镇化效率情况提 出以下建议: (1) 发挥区位优势, 加 大金融支持。西部地区的经济水平较 东部地区相对落后，且金融支持能力 较弱。因此, 西部地区各省应该充分 发挥其区位优势, 合理利用其自然资 源与矿产资源，大力发展旅游产业、 特色农产品产业、文化产业等特色优 势产业，以满足自身对资金的需求。 同时政府应该加大对基础设施的资金 投资力度。（2）合理配置资源，加强 技术开发，提高管理水平。西部地区 半数省份 2015 年出现产出不足和投入 冗余的情况, 大部分省份也出现了城 镇化的规模报酬递减现象, 这就需要 政府与相关部门提高其管理水平，加 大对技术发展的投入，提高资源利用 效率, 进而提高城镇化的全要素生产 效率, 同时加快各省的城镇化进程。

\section{参考文献}

[1] 魏后凯.怎样理解推进城镇化健康发 展是结构调整的重要内容 $[\mathrm{J}]$.中 州建设,2005(4):429-444.

[2] Charnes A, Cooper W W, Rhodes E. Measuring the efficiency of decision-making units $[\mathrm{J}]$. European Journal of Operational Research, 1978, 6(2):429-444.

[3] Banker R D, Charnes A, Cooper W W. Some models for estimating technical and scale inefficiencies in data envelopment analysis [J].Management Science, 1984, 30(9):1078-1092.

[4] 王家庭,赵亮.我国区域城市化效率 的动态评价 $[\mathrm{J}]$. 软科学, 2009(7).

[5] 李红锦,李胜会.基于 DEA 模型的城 市化效率实证研究——我国三大 城市群的比较 $[\mathrm{J}]$. 大连理工大学 学报（社会科学版）,2012(3).
[6] 张明斗.中国城市化效率的时空分异 与作用机理 $[\mathrm{J}]$. 财经问题研 究,2013(10).

[7] 张荣天,焦华富.长江三角洲地区城 镇化效率测度及空间关联格局分 析 [J].地理学.2015(4):433-439.

[8] 宋林,张洋,郭玉晶.环境约束下陕西 城镇化效率的区域差异及空间格 局 [J] .人文理.2016(6):115-122.

[9] 魏后凯, 苏红键, 韩镇宇.中国城镇化 效率评价分析一一基于资源环境 效率的视角 $[\mathrm{J}]$.中国地质大学学 报.2017(3):66-73. 